\title{
IMPLEMENTASI TUGAS POKOK DAN FUNGSI PENGAWAS MADRASAH DALAM PENINGKATAN MUTU MADRASAH ALIYAH SE-KECAMATAN TANETE RIATTANG KABUPATEN BONE
}

\author{
ERWIN, SYAHRUDDIN USMAN, MISYKAT MALIK IBRAHIM \\ Pascasarjana UIN Alauddin Makassar \\ Email: hmierwin@gmail.com, tks.syahruddin.usman@uin-alauddin.ac.id, \\ misykat.mmi@gmail.com \\ (Article History) \\ Received August 06, 2020; Revised November 28, 2020; Accepted November 28, 2020
}

\begin{abstract}
:
The problem of this research is on the roles and functions of madrasah supervisors in improving the quality of Madrasah Aliyah in Tanete Riattang district of Bone regency. It's important to know the understanding of supervisors on their roles and functions in improving the quality of schools, the planning of supervisors in conducting their roles and functions, and the implementation of supervision in improving the quality of Madrasah Aliyah in Tanete Riattang district of Bone regency. This reseach was a qualitative research where the main sources of the research data were the head of the Ministry of Religious Affairs of Bone, Madrasah supervisors, Principals, teachers, and staffs of Madrasah Aliyah in Tanete Riattang district. Data processing and analysis techniques were carried out through three stages of data reduction, data display, and data conclusion drawing. The results of this research showed that the supervisors' understanding was monotonous in which the supervisors prepared their programs according to the supervisory standard. In addition, the supervisors merely made a one-time visit to 24 different madrasas which could be considered to be inefffective.
\end{abstract}

Keywords: Supervisors, Roles, Functions, Madrasah Quality

\section{PENDAHULUAN}

- ksistensi lahirnya madrasah memiliki sejarah yang sangat panjang dalam peradaban islam. Hal ini memberikan konstribusi yang sangat besar pula pada wilayah intelektual Islam. Madrasah adalah regenerasi institusi pendidikan Islam sebelumnya, seperti mesjid, ribath, khan, rumah sakit, halaqah, shuffah dan kuttab. Tujuan pendidikan ketika itu adalah untuk menanamkan akidah Islam, menghapus kebodohan dan menyebarkan hikmah (Sutrisno, 2015). Meskipun tradisi keilmuan secara langsung tidak lahir di institusi madrasah, dikarenakan madrasah langsung diatur oleh pemerintah, namun melalui institusi ini telah menumbuhkan kecintaan dan gairah para intelektual Islam terhadap ilmu pengetahuan. Ini terbukti dari karya-karya mereka dari berbagai bidang ilmu baik ilmu agama maupun ilmu pengetahuan (sains). 
Pengawas merupakan pegawai negeri sipil yang memiliki tugas dan tanggung jawab melakukan pengawasan akademik dan manajerial pada madrasah, sehingga peranan pengawas dalam mencapai mutu madrasah sangat penting. Saputra (2016) mengatakan "Pengawas pendidikan merupakan salah satu faktor kunci yang membantu lembaga pendidikan mencapai tujuannya". Begitu pula pengawas madrasah dan pendidikan agama Islam. Selain itu, mutu pendidikan dapat pula dipengaruhi oleh beberapa faktor diantaranya kualitas kepala madrasah, guru, siswa, wali murid, komite madrasah, masyarakat, pemerintah, proses pembelajaran, sarana dan prasarana, maupun dari segi prestasi akademik dan non akademik.

Mengutip pernyataan Sabandi (2013) yakni "Supervisi pendidikan memegang peranan penting dalam meningkatkan kualitas pembelajaran guru yang pada akhirnya menghasilkan prestasi belajar siswa yang tinggi”. Pelaksanaan supervisi pendidikan oleh pengawas selain bertujuan untuk membantu guru-guru dalam mengembangkan profesinya juga untuk mengembangkan pribadi serta sosialnya agar sekolah yang menjadi binaannya dapat mencapai peningkatan mutu. Selain itu, kegiatan supervisi memiliki tujuan untuk membantu kepala sekolah dalam hal menyesuaikan program pendidikan dengan kondisi masyarakat setempat, dan juga ikut berjuang dalam proses meningkatan kualitas dan kuantitas lulusan (Pidarta, 2009).

Pengawas berarti orang yang mengawasi. Pengawas madrasah adalah guru pegawai negeri sipil yang diangkat dalam jabatan fungsional pengawas satuan pendidikan yang tugas, tanggung jawab, dan wewenangnya melakukan pengawasan akademik dan manajerial pada madrasah. Pengawas madrasah adalah guru berstatus pegawai negeri sipil yang diangkat dan diberi tugas tanggung jawab serta wewenang untuk melaksanakan pengawasan akademik dan manajerial pada satuan pendidikan madrasah. Ahmad (2015) mengatakan "Efektivias organisasi merupakan tingkat keberhasilan kegiatan manajemen dalam usaha mencapai tujuan atau sasaran yang telah diprogramkan". Faktor yang menentukan dan terlibat dalam pendidikan di madrasah yaitu pengawas. Keberhasilan pengawas baik supervisi akademik dan supervisi manajerial menciptakan iklim pembelajaran yang kondusif (Mudzakir, 2016).

Tanggung jawab seorang pengawas madrasah adalah melaksanakan supervisi akademik dan manajerial (Muzayanah, 2016). Pengawas yang sangat baik sangat berpengaruh pada performance guru. Tugas pengawas mencakup tugas pokok inspecting (menyupervisi) meliputi tugas menyupervisi kinerja kepala sekolah, kinerja guru, kinerja staf sekolah, pelaksanaan kurikulum atau mata pelajaran, pelaksanaan pembelajaran, ketersediaan dan pemanfaatan sumber daya, manajemen sekolah, serta aspek lainnya seperti keputusan moral, pendidikan moral dan kerjasama dengan masyarakat. Ismail (2016) mengatakan “Untuk meningkatkan mutu pendidikan yang ada di madrasah, maka diperlukan adanya sebuah kepengawasan agar bisa melihat perkembangan dan kemajuan peserta 
didik, dan juga berjalan atau tidak berjalannya sebuah madrasah". Dari gambaran uraian pengawas di atas, tentu yang menjadi poin penting tugas pokok pengawas adalah advising, monitoring, tugas pokok reporting, tugas pokok coordinating, tugas pokok performing leadership. Dengan demikian pengawas mengamati semua rangkaian aktivitas warga madrasah, baik dari segi pelaksana supervisi akademik maupun supervisi manajerial.

Rahmah (2018) mengatakan bahwa "Pendidikan adalah elemen terpenting bagi suatu negara dalam menunjukkan eksistensinya sebagai negara yang memiliki integritas dan mampu bersaing dengan negara maju lainnya di dunia". Maujud (2018) mengatakan bahwa "Fungsi pengawasan dilakukan dengan mengontrol kuantitas dan kualitas kerja personil melalui supervisi kelas, rapat kerja guru dan kepala madrasah, serta audit penggunaan anggaran dilakukan melalui rapat bersama komite madrasah". Manajemen kinerja adalah proses kerja pengawas terhadap tugas pokok dan fungsi yang telah diamanahkan (Chadidjah, 2017). Berdasarkan Peraturan Pemerintah Nomor 19 Tahun 2005, Pasal 55 disebutkan bahwa "Peran pengawas madrasah meliputi pemantauan, supervisi, evaluasi, pelaporan, dan tindak lanjut pengawasan yang harus dilakukan secara berkesinambungan". Pengawas dalam menjalani tugas dan fungsinya ke madrasah, diperlukan adanya kinerja profesional pengawas, sehingga berkontribusi terhadap mutu pendidikan. Fungsi pengawasan dilakukan dengan mengontrol kuantitas dan kualitas kerja personil melalui supervisi kelas, rapat kerja guru dan kepala madrasah, serta audit penggunaan anggaran dilakukan melalui rapat bersama komite madrasah. Dalam melaksanakan fungsi supervisi akademik, pengawas berperan sebagai mitra guru dalam meningkatkan mutu proses dan hasil pembelajaran dan bimbingan di sekolah binaannya, inovator dan pelopor dalam mengembangkan inovasi pembelajaran dan bimbingan di sekolah binaannya, konsultan pendidikan di sekolah binaannya, konselor bagi kepala madrasah, guru, dan seluruh staf sekolah, dan motivator untuk meningkatkan kinerja semua staf sekolah. Madrasah dipandang sebagai lembaga yang khusus mentransmisikan ilmuilmu agama dengan memberikan penekanan khusus pada bidang fikih, tafsir, hadis dan tidak memasukkan ilmu-ilmu umum dalam kurikulum (Sulastri, 2016). Hidayatil (2018) mengatakan "Pengawas dalam menjalani tugas dan fungsinya ke madrasah, diperlukan adanya kinerja professional pengawas, sehingga berkontribusi terhadap mutu pendidikan". Lebih lanjut, Saifurrahman (2017) mengatakan "Proses memberi bantuan dilakukan secara alamiah dengan target member solusi terhadap problem yang dimiliki antara yang melakukan supervisi (supervisor) dengan yang disupervisi (guru) harus ada kesejajaran (pararel) dan lebih mengedepankan pendekatan profesional daripada pendekatan birokratif".

Dalam proses belajar mengajar, peran supervisi pengawas madrasah memiliki peran strategis dalam meningkatkan mutu pendidikan demi mensukseskan tujuan pendidikan nasional. Marjoko, Soegito, dan Retnaningdyastuti (2017) mengatakan 
"Mutu pendidikan adalah suatu proses dari hasil pendidikan yang diukur berdasarkan relevansi keefektifan dan dampak dari program, proses atau tindakan dalam rangka mencapai tujuan pendidikan yang memenuhi keinginan dan kebutuhan pelanggan sesuai dengan standar pelayanan minimal (SPM) dan standar nasional pendidikan (SNP)". Supervisi memberikan layanan terhadap guru yang mendapat kesulitan atau terjadi penurunan dalam kompetensinya (Muslim, 2018). Pada supervisi manajerial adalah merupakan fungsi supervisi yang berkenaan dengan aspek pengelolaan sekolah yang terkait langsung dengan peningkatan efesiensi dan efekivitas sekolah yang mencakup perencanaan, koordinasi, pelaksanaan, penilaian, pengembangan kompetensi sumber daya manusia kependidikan dan sumber daya lainnya.

Hasil observasi penulis dari tiga Madrasah Aliyah se-Kecamatan Tanete Riattang Kabupaten Bone, pengawas dalam menjalankan tugasnya di tiga madrasah binaannya kurang melakukan pendekatan secara emosional kepada pihak guru dengan tujuan untuk meningkatkan kualitas guru binaannya. Keberadaan pengawas dianggap tidak terlalu memberikan sumbangsih baik terhadap perkembanan pendidikan di mardasah. Kemudian terjadi pula hal lain terkait ketidaksesuaian antara teori dengan pengaplikasian lapangan. Pengawas selaku penyampai informasi terkait kebijakan kementerian agama kepada madrasah, begitu pun sebaliknya pengawas juga mesti menyampaikan aspirasi dari pihak madrasah kepada kementerian agama. Pengawas diharapkan aktif mengawasi pelaksanaan kebijakan dengan cara mencari data masukan customer pendidikan dalam menyikapi program di sekolah. Tidak diharapkan, pengawas hanya melaksanakan kunjungan rutin tanpa menyentuh teknis pengajaran dan pengendalian mutu pendidikan. Terkait mutu pendidikan, akan dianggap berkembang atau terbilang berprestasi jika memenuhi beberapa unsur yakni prestasi akademik dan prestasi non akademik. Prestasi akademik meliputi nilai ulangan umum, ujian akhir nasional, karya ilmiah dan lomba akademik. Prestasi non akademik seperti IMTAQ, kejujuran, kesopanan, olahraga, kesenian, keterampilan kejuruan, dan kegiatan-kegiatan ekstrakurikuler lainnya. Sedangkan faktor yang mempengaruhi mutu pendidikan secara keseluruhan ada dua yaitu faktor internal dan fakor eksternal. Faktor internal meliputi inteligensi, bakat, minat dan motivasi yang akan berpengaruh besar pada tinggi rendahnya proses perubahan mutu. Faktor eksternal meliputi keadaan keluarga, keadaan madrasah dan lingkungan masyarakat. Namun tugas terpenting seorang pengawas adalah melakukan proses pembinaan, pembimbingan serta pengembangan madrasah, karena pada dasarnya bahwa setiap madrasah memiliki masalah yang berbeda, sehingga dalam memberikan solusi pun harus berbeda. Alasan ini kemudian yang membuat peneliti tertarik untuk mengetahui lebih jauh terkait implementasi tugas pokok dan fungsi pengawas madrasah aliyah di Kecamatan Tanete Riattang Kabupaten Bone. Tujuan penelitian ini mengetahui pemahaman, perencanaan dan pelaksanaan pengawas mengenai tugas pokok dan 
fungsi pengawas madrasah dalam peningkatan mutu madrasah, mengetahui perencanaan program pengawasan tugas pokok dan fungsi pengawas madrasah dalam peningkatan mutu madrasah, mengetahui pelaksanaan pengawasan guna peningkatan mutu Madrasah Aliyah se-Kecamatan Tanete Riattang Kabupaten Bone.

\section{METODE PENELITIAN}

Penelitian ini dilakukan dengan menggunakan jenis penelitian lapangan (field research) dengan deskripif kualitatif. Proses analisis data dalam penelitian kualitatif yang akan dilakukan penulis dengan menelaah seluruh data yang terkumpul dari berbagai sumber, yaitu dari wawancara. Beberapa responden diantaranya pengawas madrasah, kepala madrasah, wakil kepala madrasah, guru dan staf madrasah. Penelitian ini dilakukan di tiga madrasah yakni Madrasah Aliyah Negeri 1 Watampone, Madrasah Aliyah Negeri 2 Watampone dan MA Al-Junaidiyah Biru Bone.

\section{HASIL PENELITIAN DAN PEMBAHASAN}

Berdasarkan aturan yang ditetapkan oleh Kementerian Pendidikan dan Kebudayaan tahun 2014 yang dikutip sebagai berikut bahwa "Pengawas madrasah yang berstatus pegawai negeri sipil yang diberi tugas tanggung jawab secara penuh oleh pejabat yang berwenang untuk melaksanakan pengawasan akademik dan manajerial pada satuan pendidikan". Pengawas harus memahami tugas yang diamanahkan oleh undang-undang yakni bertugas melakukan pengawasan akademik dan manajerial. Tentu hal ini harus dilakukan dengan metode yang tepat, sehingga guru-guru madrasah tidak sekedar memperbaiki laporan hanya pada saat pengawas berkunjung ke madrasah. Dalam konteks pemahaman, pengawas kurang memahami secara keseluruhan tentang konsep kepengawasan, sehingga kepengawasannya terkesan monoton dan kaku (Partisipan Gusnaedi, diwawancara tanggal 25 Februari 2020). Ismail (2018, h. 59) mengatakan bahwa “Dalam dunia bisnis mutu adalah kepuasan pelanggan, jika diterjemahkan dalam dunia pendidikan adalah kepuasan masyarakat (stakeholders) terhadap output dari lembaga pendidikan itu sendiri".

Fungsi pengawas madrasah diantaranya pembinaan dan pengembangan madrasah. Madrasah dalam hal ini adalah tempat belajar tingkat menengah yang pengawas harus pahami model seperti apa yang diperlukan dan proses pengembangannya. Ditambah lagi pada era globalisasi saat ini tuntutan zaman yang membuat semuanya harus cepat berkembang. Pembinaan, pembimbingan dan pengembangan guru madrasah juga adalah salah satu fungsi terpenting bagi kehadiran pengawas. Namun dalam hal ini pengawas memahami bahwa posisinya adalah sebagai penegak undang-undang dalam hal pengawasan. Mengawasi kinerja guru-guru madrasah. Fungsi pengawas selanjutnya adalah pemantauan penerapan standar nasional pendidikan. Fungsi inilah yang kemudian menjadi penentu 
IMPLEMENTASI TUGAS POKOK DAN FUNGSI PENGAWAS ...

keberhasilan dalam proses pengawasan dan untuk memaksimalkan kepengawasannya.

Penyusunan Program Perencanaan Pengawasan

Program Tahunan dan Semester Pengawas Madrasah Wilayah I Tahun Pelajaran 2018/2019

Penyusunan RKS, RKT, RKAS dengan memantau dan membimbing pengawasannya. Melaksanakan pembimbingan terhadap guru dengan cara mengadakan bimbingan dan monitoring hasil kegiatan KKG dan MGMP. Mengumpulkan dan mengelola sumber daya pendidikan dan proses belajar mengajar di lingkungan madrasah yang berpengaruh pada hasil belajar siswa melalui observasi, monitoring dan wawancara. Melaksanakan pembinaan dan pendampingan guru di madrasah tentang pelaksanaan KBM berbasis karakter dengan melakukan kunjungan kelas, rapat dan diskusi dengan guru-guru. Memberi contoh pelaksanaan tugas guru dalam mengajar serta memberikan saran kepada lembaga terkait untuk meningkatkan kemampuan profesionalisme guru dengan melakukan kunjungan dan merumuskan saran-saran berdasarkan hasil kepengawasan. Pengawas menyusun program tahunan dengan mengadakan diskusi, menganalisa hasil evaluasi kepengawasan. Monitoring dan pembinaan penerimaan mahasiswa baru dengan memantau dan mengikuti pedoman penerimaan siswa baru. Melakukan sosialisasi penyusunan KTSP dengan mengadakan pertemuan bersama kepala madrasah. Administrasi pembelajaran (kurikulum) dengan memantau dan memonitor ketersediaan silabus dan RPP (Partisipan Arifin, diwawancara tanggal 28 Februari 2020).

\section{Persiapan Instrumen-Instruumen Pengawas Madrasah}

Dalam mempersiapkan instrument-instrumen kepengawasan, pengawas telah menyusun instrumen kepengawasan mulai dari hal administrasi kurikulum dan pembelajaran, administrasi kelas, administrasi manajemen madrasah, adminisrasi organisasi dan kelembagaan, sarana dan prasarana, ketenagaan, pembiayaan, peserta didik, dan lingkungan budaya sekolah.

Tabel 1. Instrumen-instrumen Pengawas Madrasah Aliyah se-Kecamatan Tanete Riattang Kabupaten Bone

\begin{tabular}{ll}
\hline I. & \multicolumn{1}{c}{ Instrumen Pembelajaran Terkait Administrasi dan Kurikulum } \\
\hline & Aspek/Komponen \\
\hline & Administrasi Kurikulum \\
Memiliki dokumen KTSP, kurikulum \\
Memiliki tim jaringan/pengembangan kurikulum \\
Memiliki kalender pendidikan \\
Memiliki program pengembangan diri \\
Administrasi Pembelajaran \\
Memiliki dokumen silabus yang disusun oleh guru \\
Memiliki dokumen RPP yang disusun oleh guru \\
Memiliki jadwal pelajaran secara tertulis \\
Memiliki jadwal pengembangan diri secara tertulis
\end{tabular}


Melaksanakan ulangan harian, tengah semester dan semester

Memiliki dokumen soal ulangan harian, tengah semester dan semester

II.

Program Kerja

Instrumen Administrasi dan Manajemen Sekolah

Program jangka panjang madrasah, jangka pendek serta proram tahunan

Program madrasah meningkatkan mutu

Madrasah harus memiliki program supervisi inrenal dan tidak lanjut

Madrasah memiliki RAPBS dan program kerja TU

Pembinaan

Madrasah mengikut sertakan guru dalam pelatihan untuk meng-upgrade kualitas

serta kemampuan mengajarnya

Madrasah menfasilitasi guru untuk melanjutkan studi

Madrasah melibatkan guru senior dalam supervisi

Madrasah memiliki buku catatan pembinaan kapada guru dan pegawai dan kasus

\begin{tabular}{|c|c|}
\hline III. & Instrumen Organisasi dan Kelembagaan \\
\hline & Aspek/Komponen \\
\hline & Organisasi \\
\hline & Sekolah memiliki bagan dan struktur organisasi penyelenggara/pengelola \\
\hline & Sekolah memiliki struktur dan bagan komite sekolah, struktur OSIS, Lab, \\
\hline & perpustakaan. \\
\hline & Sekolah memiliki struktur tata usaha \\
\hline & Sekolah memiliki struktur komite sekolah \\
\hline & Kelembagaan \\
\hline & Memiliki akte pendirian sekolah, sertifikat tanah dan master plan. \\
\hline & $\begin{array}{l}\text { Mengadakan kerjasama dengan lembaga pendidikan lain dalam } \\
\text { mengembangkan sekolah }\end{array}$ \\
\hline & Membangun mitra dengan lembaga eksternal \\
\hline & MOU sebagai bukti kesepakatan rekan kerja \\
\hline IV. & Instrumen Sarana dan Prasarana \\
\hline & Aspek/Komponen \\
\hline & Kepemilikan gedung, halaman \\
\hline & Ruang praktek dan taman baca serta wc \\
\hline & Memiliki instalasi listrik, air, telepon \\
\hline & Memiliki lapangan olahraga, seni \\
\hline & Memiliki ruang kepala sekolah, ruang UKS, BK, kantin, parkir \\
\hline V. & Instrumen Pembiayaan \\
\hline & Aspek/Komponen \\
\hline & Rasio guru dan siswa $(1: 36)$ \\
\hline & $\begin{array}{l}\text { Memiliki tenaga khusus administrasi sekolah, kebersihan serta pengamanan } \\
\text { sekolah }\end{array}$ \\
\hline & Memiliki tenaga pelatihan pramuka \\
\hline VI. & Instrumen Lingkungan Budaya Sekolah \\
\hline & Aspek/Komponen \\
\hline & Madrasah memiliki RAPBS \\
\hline & $\begin{array}{l}\text { Pengelolaan segala bentuk penganggaran sesuai dengan RAPBS baik dari pusat, } \\
\text { provinsi maupun daerah }\end{array}$ \\
\hline
\end{tabular}

Sumber: Kementerian Agama Kabupaten Bone (2018/2020) 
Pengawas dalam hal menyusun program perencanaan pengawasan dilihat dari penyusunan program tahunan, penyusunan program semester dan persiapan instrumen-instrumen pengawasan sesuai data yang diperoleh peneliti dan hasil penelitian, telah menunjukkan bahwa secara terstruktur telah dibuat sesuai dengan standar program perencanaan pengawasan (Partisipan Arifin, diwawancara tanggal 28 Februari 2020).

Pengawas madrasah menyusun program perencanaan pengawasan dalam bentuk tabel, sehingga dalam proses pelaksanaannya memiliki acuan yang konsisten dan terstruktur. Metode penentuan kesuksesan supervisi manajerial setiap madrasah tertuang dalam poin penilaian pengawas. Pengawas menilai setiap aspek atau tiap komponen dengan kualifikasi skor 1 sampai 5 . Kemudian mengakumulasi secara keseluruhan perolehan nilai di setiap aspek komponennya. Tahar selaku Wakamad Kurikulum mengatakan bahwa dalam proses kepengawasan pengawas madrasah, Arifin selaku Pengawas terbilang aktif, namun tidak menindaklanjuti terkait pengembangan madrasah (Partisipan Tahar, diwawancara tanggal 25 Februari 2020).

Terkait sarana dan prasarana, Partisipan Rubaedah (diwawancara tanggal 27 Februari 2020) mengatakan bahwa kondisi kursi dan meja siswa terbilang cukup. Dengan jumlah siswa idealnya 36 per kelas telah difasilitasi meja dan kursi yang memadai, sehingga dalam proses belajar mengajar, siswa tidak merasa teraganggu.

\section{Pelaksanaan Pengawasan}

Pengawas dalam proses pengawasannya menekankan kepada guru-guru agar memperhatikan daftar hadir, RPP, analisis ulangan harian siswa dan lainnya harus disiapkan. Mahmud selaku Wakamad Humas berharap besar bahwa pengawas dalam hal ini pengawas lebih fokus pada memberikan pendampingan setiap elemenelemen dalam madrasah. Pelaksanaan pengawasan yang berkualitas akan menunjang proses peningkatan mutu madrasah (Partisipan Fadli, diwawancara tanggal 3 Maret 2020). Baik dari pihak kurikulum, kesiswaan, sarana dan prasarana, begitupun humas (Partisipan Abbas, diwawancara tanggal 28 Februari 2020). Kehadiran pengawas sebagai salah satu fungsional madrasah yang sangat penting telah memberikan perubahan positif. Sejalan dengan PP Nomor 19 Tahun 2005 tentang Standar Mutu Pendidikan yang dikutip, yakni "Peran pengawas satuan pendidikan sangat penting dalam meningkatkan mutu pendidikan pada satuan pendidikan binaannya". Mutu madrasah binaan pengawas terbilang meningkat. Opini publik tentang posisi pengawas hanya sebatas tempat memarkir jabatan yang hampir pensiun, dijawab tegas oleh Abbas tidak benar. Dengan dasar bahwa segala bentuk mekanisme pengangkatan pengawas telah diatur dalam regulasi. Pengawas dalam mengemban amanah kepengawasan harus intensif, lebih lagi pada persoalan pemantauan. Penguasaan ilmu pengetahuan dan teknologi menjadi penunjang besar dalam proses pengawasan pengawas madrasah. Dengan demikian tentu 
pengawas harus memiliki pengetahuan lebih dalam proses pengawasan sesuai dengan regulasi yang mengaturnya.

\section{PENUTUP/SIMPULAN}

Pengawas madrasah memahami regulasi tentang tugas pokok dan fungsi pengawas madrasah namun masih terkesan monoton dan kaku, sehingga dalam proses pelaksanaan kepengawasannya tidak tercipta nilai-nilai kreativitas dan inovatif. Pengawas madrasah dalam hal perencanaan program kepengawasan telah membuat daftar instrumen kepengawasan, daftar kerja tahunan maupun semester. Pengawas dalam hal ini menyusun sedemikian rupa terkait program perencanaan pengawasan dalam bentuk tabel, sehingga dalam proses pelaksanaannya memiliki acuan yang konsisten dan terstruktur. Pelaksanaan kepengawasan di Madrasah Aliyah Negeri 1 Bone, Madrasah Aliyah Negeri 2 Bone dan Madrasah Aliyah AlJunaidiyah Biru Bone berjalan kurang maksimal karena masih terdapat beberapa kekurangan diantaranya metode kepengawasan yang diterapkan tidak mengikuti pola perkembangan yang ada. Model kepengawasan masih terkesan sangat tradisonal.

Kepada Kementerian Agama selaku pihak yang memiliki wewenang baiknya melakukan pengangkatan dan penambahan jumlah pengawas madrasah yang telah memenuhi syarat dan kompetensi pengawas. Kepada pengawas madrasah agar adaptif terhadap perkembangan zaman, sehingga terbentuk kreativitas, edukatif, realistis dan efektivitas dalam memberikan pembinaan, pembimbingan dan arahan kepada kepala sekolah dan guru MAN 1 Watampone, MAN 2 Watampone dan MA AlJunaidiyah Biru untuk lebih meningkatkan mutu madrasah. Kepada warga madrasah baiknya memperhatikan saran serta petunjuk yang diberikan pengawas serta membangun hubungan emosional yang baik sebagai penunjang jangka panjang dalam proses peningkatan mutu madrasah. Dengan selesainya penelitian ini besar harapan peneliti kiranya hasil penelitian ini dapat menjadi referensi bagi penerus pendidikan di seluruh penjuru dunia. Terkhusus kepada peneliti selanjutnya agar lebih memperdalam lagi terkait permasalahan yang akan diteliti, sehingga dalam prosesnya tidak terjadi kekeliruan pemahaman dan berujung pada penyelesaian penelitian yang bermanfaat pula.

\section{DAFTAR PUSTAKA}

Ahmad, S. (2015). Hubungan Prilaku Pengawas, Keterampilan Manajerial Kepala Madrasah dan Motivasi Berprestasi Guru dengan Efektivitas Organisasi Madrasah Aliyah se-Kota Banjarmasin. Management of Education, 1(2), 5471.

Chadidjah, S. (2017). Manajemen Kinerja Pengawas Madrasah Aliyah Swasta di Kota Bandung. UIN Sunan Gunung Djati Bandung. 
Maujud, Fathul. (2018). Implementasi Fungsi-fungsi Manajemen dalam Pendidikan Islam (Studi Kasus Pengelolaan Madrasah Ibtidaiyah Islahul Muta 'allim Pagutan). Jurnal Penelitian Keislaman, 14(1), 30-50. Retrieved from https://journal.uinmataram.ac.id/index.php/jpk/article/view/490

Hidayatil, H. (2018). Pelaksanaan Pengawasan oleh Pengawas Madrasah terhadap Kinerja Guru di MTs Al-Furqan Kota Padang. Universitas Andalas.

Ismail, F. (2018). Implementasi Total Quality Management (TQM) di Lembaga $\begin{array}{llll}\text { Pendidikan. Jurnal Ilmiah } & \end{array}$ https://doi.org/10.30984/jii.v10i2.591

Ismail, I. (2016). Kinerja Pengawas Madrasah dalam Meningkatkan Kompetensi Guru Madrasah di Kabupaten Gorontalo. Jurnal IImiah AL-Jauhari: Jurnal Studi Islam Dan Interdisipliner, 1(1), 83-95.

Kementerian Agama Kabupaten Bone. Petunjuk Teknis Pengawas Madrasah Tahun 2018/2020. , (2020).

Marjoko, M., Soegito, S., dan Retnaningdyastuti, R. (2017). Strategi Peningkatan Budaya Mutu Madrasah Aliyah Negeri di Kota Semarang. Jurnal Manajemen Pendidikan (JMP), 5(2), 150-165. https://doi.org/10.26877/jmp.v5i2.1930

Mudzakir, D. (2016). Implementasi Supervisi Manajerial Dan Akademik Pengawas Dalam Meningkatkan Kinerja Guru Pendidikan Agama Islam Madrasah Ibtidayah. Studia Didaktika, 10(02), 33-47.

Muslim, M. (2018). Peran Supervisi Pengawas Madrasah dalam Meningkatkan Mutu Pendidikan: Studi pada Madrasah Aliyah Negeri 3 Kabupaten Tasikmalaya. Indonesian Journal of Education Management \& Administration Review, 1(1), 55-62.

Muzayanah, U. (2016). Kualitas Kinerja Pengawas Madrasah dalam Perspektif Guru dan Kepala Madrasah (Analisis Perbandingan Kepuasan Guru dan Kepala MI terhadap Supervisi Pengawas Madrasah di Sukoharjo dan Surakarta Jawa Tengah). Al-Qalam, 22(2), 269-280. https://doi.org/10.31969/alq.v22i2.318

Pidarta, M. (2009). Landasan kependidikan: stimulus ilmu pendidikan bercorak Indonesia. Rineka Cipta.

Rahmah, S. (2018). Pengawas Sekolah Penentu Kualitas Pendidikan. JURNAL TARBIYAH, 25(2), 174-193. https://doi.org/10.30829/tar.v25i2.378

Sabandi, A. (2013). Supervisi Pendidikan Untuk Pengembangan Profesionalitas Guru Berkelanjutan. PEDAGOGl: Jurnal IImiah IImu Pendidikan, XIII(2), 1-9. Retrieved from http://ejournal.unp.ac.id/index.php/pedagogi/article/view/4275/3345 
Saifurrahman, S. (2017). Pengaruh Supervisi Pengawas Madrasah dan Motivasi Berprestasi Guru Terhadap Kinerja Guru Madrasah Aliyah Negeri di Kabupaten Barito Kuala. Pascasarjana.

Saputra, M. A. (2016). Kompetensi Pengawas Madrasah dan PAl di Kabupaten Bone, $\begin{array}{llll}\text { Sulawesi Selatan. } & \text { Al-Qalam, }\end{array}$ https://doi.org/10.31969/alq.v18i2.80

Sulastri, T. (2016). Fungsi Madrasah dalam Pengembangan IImu Pengetahuan Islam. QATHRUNÂ, 3(02), 127-142.

Sutrisno. (2015). Penilaian pembelajaran tematik pada kurikulum 2013 di sekolah dasar. Jurnal Sekolah Dasar, 24(1), 12-17. Retrieved from http://journal2.um.ac.id/index.php/sd/article/view/1345/706 